\title{
Preparation of polymer-rare earth complexes based on Schiff-base-containing salicylic aldehyde groups attached to the polymer and their fluorescence emission properties
}

https://doi.org/10.1515/epoly-2019-0003

Received June 15, 2018; accepted October 23, 2018.

\begin{abstract}
In this study, the salicylaldehyde hydrazone was bonded onto the side chains of poly (styrene-co-butyl acrylate), firstly obtaining a series of novel Schiff basefunctionalized polymers. and using the base-containing polymers as macromolecular ligands through further reaction with $\mathrm{EuCl}_{3} / \mathrm{YbCl}_{3} \cdot 6 \mathrm{H}_{2} \mathrm{O}$, a series of polymer-rare earth complexes based on $\mathrm{Eu}(\mathrm{III}) / \mathrm{Yb}$ (III) ion were successfully prepared. The structures of the schiff base-containing polymers and their corresponding complexes were characterized by means of infrared spectra and UV spectra. The thermal properties of the functionalized polymers and complexes were investigated by TGA, and the fluorescence properties of the complexes were also researched by fluorescence spectrum. The experimental results show that the complexes have fine thermal stability likely because of the bidentate chelate effect of base-containing polymer and the conjugative effect of salicylaldehyde hydrazone group on the side chain of poly (styrene-co-butyl acrylate). More important, the salicylaldehyde hydrazone group on the side chains of poly(styrene-co-butyl acrylate) can efficaciously sensitize the fluorescence emission of the center ion due to effective intramolecular energy transfer. All the $\mathrm{Eu}(\mathrm{III}) / \mathrm{Yb}(\mathrm{III})$ complexes exhibit characteristic
\end{abstract}

\footnotetext{
* Corresponding author: Dingjun Zhang, State Key Laboratory of Advanced Processing and Recycling of Non-ferrous Metals, Lanzhou University of Technology, Lanzhou 730050, China, e-mail: zhangdingjunlut@163.com.

Wenjin Zhao, Zhaoxuan Feng, Youzhi Wu, Ling He and Wenjiang Lu, State Key Laboratory of Advanced Processing and Recycling of Non-ferrous Metals, Lanzhou University of Technology, Lanzhou 730050 , China.

Caixia Huo, China School of Chemistry and Environment Science, Lanzhou City University, Lanzhou 730070, China.
}

photoluminescence peaks in the visible region. The fluorescence excitation spectra of the complexes were obtained by monitoring the emission of $\mathrm{Eu}^{3+} / \mathrm{Yb}^{3+}$ ion at $497 \mathrm{~nm}$, and the peak at $433 \mathrm{~nm}$ was found to be the optimal excitation peak. The concentration of salicylaldehyde hydrazone group was changed gradually with the variation of the molar ratio between the butyl acrylate and styrene (1:0.5; $1: 1 ; 1: 1.5 ; 1: 2 ; 1: 2.5)$, and the differences in their fluorescent intensity were followed, and the fluorescence intensity was very weak when the molar ratio of the butyl acrylate to styrene is equal to $1: 2.5$, while the fluorescence intensity reached a maximum value in the molar ratio of 1:1.

Keywords: rare earth complex; Schiff base-containing preparation; fluorescence emission property

\section{Introduction}

Since early 1963, Wolff and Pressley (1) had studied the fluorescence properties of $\mathrm{Eu}^{3+}$ containing poly (methyl methacrylate) (PMMA). As new functional materials, polymer rare earth complex materials have drawn much attention because of it's unique fluorescence properties, like good mechanical toughness, good chemical stability, and excellent processability, as well as their potential applications in the fields of photoluminescence,electrol uminescence, optics communications, lasers, and solarenergy conversion systems (2-6). The study of polymerbased rare earth complexes luminescent materials has always been an active research area. A large amount of reports on polymer-based rare earth fluorescence materials have appeared in the literature $(7,8)$.

Most of the polymer matrixes in the previous investigations were aliphatic polymers such as poly (methyl methacrylate) (PMMA), polystyrene (PS), 
polyacrylic acid (PAA) and their copolymers (9-12). The ligands attached onto polymer skeletons are usually aliphatic carboxylic groups. Aliphatic carboxylic groups not only can coordinate to rare earth ions, but also has no energy transfer action or sensitization action for the emission of rare earth ions due to their very poor UV absorptions (13-15). Therefore for these systems, only a few small-molecule ligands such as 1, 10-phenanthroline and $\beta$-diketone are used as synergistic co-ligands, which can make luminescent polymer-rare earth complexes formed $(16,17)$.

Nowadays, a number of researchers tried to chemically incorporate functionalized groups onto the polymer backbones, and made the ligands to have functions of both coordination and sensitization actions for rare earth ions (18-20). The aromatic acyl hydrazone Schiff-base compounds are also a kind of such ligands (21). In the chemical structure of the acyl hydrazone compounds, there is not only carbonyl that can coordinate to rare earth ions, but also strong intramolecular energy transfer from benzoyl to rare earth ions can occur due to their strong UV absorption coming from the larger conjugate rigid-plane structure (22-24). Aromatic acyl hydrazone Schiff base rare earth complexes exhibit highly luminescent property (25). If aromatic acyl hydrazone can be introduced into the polymer, then the polymer rare earth complexes with high performance will be obtained. Moreover, these polymer complexes possess excellent film-forming performance (26-28).

In this work, we choose styrene as monomer because styrene has good fluorescence properties, and this is mainly due to a total of four conjugated double bonds ( $\pi$ bond) on styrene, and benzene ring with large conjugated $\pi$ bond structure, and also has a conjugate $\pi$ bond on vinyl, which can jump into electronic excited singlet, belongs to the transition of $\pi \rightarrow \pi^{\star}$, and then through the decay of radiative transition process and return to the ground state, in the process with the emission of photons, which produce fluorescence. Meanwhile, in the molecular structure of styrene, carbon atoms are on the same plane, belong to the plane configuration and have certain rigidity. So, by combining the molecular design and the polymerization process, the salicylaldehyde hydrazone side chain was introduced onto the backbone of poly (styrene-co-butyl acrylate) to synthesize a series of novel Schiff base-functionalized polymers. After that, by using the Schiff base-containing polymer as macromolecular ligand, polymer rare earth complexes based on $\mathrm{Eu}(\mathrm{III}) / \mathrm{Yb}$ (III) ions were prepared. It was anticipated that the introduction of the salicylaldehyde hydrazone side chain would greatly improve the luminescence and film-forming properties of the polymer rare earth complexes. This modification promotes the application of the polymer-rare earth complexes in electrical and optoelectronic engineering.

\section{Experimental}

\subsection{Materials}

Styrene (Tianjin Kaixin Chemical Industry Co. Ltd, Tianjin, China) and butyl acrylate (Tianjin Kaixin Chemical Industry Co. Ltd, Tianjin, China) were distilled at reduced pressure. Salicylaldehyde (Tianjin Recovery of Fine Chemical Industry Research Institute, Tianjin, China), hydrazine hydrate (Tianjin Kaixin Chemical Industry Co. Ltd, Tianjin, China), dimethylformamide (Yantai Shuangshuang Chemical Co. Ltd, Yantai, China), tetrahydrofuran (Tianjin Kaixin Chemical Industry Co. Ltd, Tianjin, China), $\mathrm{Eu}_{2} \mathrm{O}_{3} / \mathrm{Yb}_{2} \mathrm{O}_{3}$ (Beijing Fandechen technology Co. Ltd, Beijing, China) were commercially purchased and used without further purification.

\subsection{Preparation of the poly (styrene-co- butyl acrylate) schiff base-containing polymer (PSCBS)}

All runs were performed in three stages. Firstly, solution copolymerization of St and BA was carried out under nitrogen atmosphere in a three-necked flask equipped with thermometer and gas inlet tube, and the benzoperoxide (Wt $=2 \%$ ) was added to the copolymer monomer solution, then keep the temperature at $80^{\circ} \mathrm{C}$ of polymerization reaction for $2.5 \mathrm{~h}$. The poly(styrene-co-butyl acrylate) was obtained after elimination of the residual monomer by washing the crude product with absolute ethyl alcohol and dried at $60^{\circ} \mathrm{C}$ to a constant weight. (The molar ratio of butyl acrylate and styrene monomers was changed from 1:0.5 to $1: 2.5)$.

Secondly, an ethanolic solution of salicylaldehyde ( $3.12 \mathrm{~g}, 25 \mathrm{mmol}$ ) was added dropwise to a solution of hydrazine hydrate $(1.56 \mathrm{ml}, 40 \mathrm{mmol})$ in ethanol (30 ml) under magnetic stirring at room temperature, and the mixture was kept for $4 \mathrm{~h}$. The solvent was distilled and the pure product was recrystallized from absolute ethanol, and dried under vacuum.

Finally, themixture of poly (styrene-co-butylacrylate) and salicylaldehyde hydrazone in tetrahydrofuran were refluxed and magnetically stirred for $24 \mathrm{~h}$. After removing the solvent by vacuum distillation, the residue was further 
purified by washing with absolute ethyl alcohol to give pale yellow solid product.

Those polymer were abbreviated as PSCBS 1-0.5 (molar ratio as 1:0.5), PSCBS 1-1 (molar ratio as 1:1), PSCBS 1-1.5 (molar ratio as 1:1.5), PSCBS 1-2 (molar ratio as 1:2), PSCBS 1-2.5 (molar ratio as 1:2.5), respectively.

\subsection{Preparation of the poly (styrene-co-butyl acrylate) Schiff base polymer -Eu(III)/Yb(III) complexes (PSCBS-Eu(III)/Yb(III))}

$\mathrm{Eu}_{2} \mathrm{O}_{3} / \mathrm{Yb}_{2} \mathrm{O}_{3}(20 \mathrm{mmol})$ was dissolved in $100 \mathrm{~mL}$ of $\mathrm{HCl}$ solution, heated and stirred for $1 \mathrm{~h}$ to make the solution transparent until crystalline grains were produced and amount of crystals formulated by $\mathrm{EuCl}_{3} / \mathrm{YbCl}_{3} \cdot 6 \mathrm{H}_{2} \mathrm{O}$ were spitting out. Then the crystals were placed in a vacuum oven to be dried

The PSCBS samples $(1.0 \mathrm{~g})$ were accurately weighed, and placed into five conical flasks of $100 \mathrm{~mL}$ capacity followed by adding $40 \mathrm{~mL}$ DMF. Under stirring, the PSCBS samples were dissolved, and the DMF solution of $\mathrm{EuCl}_{3} / \mathrm{YbCl}_{3} \cdot 6 \mathrm{H}_{2} \mathrm{O}$ with different concentrations $\left(3.4 \times 10^{-3} \mathrm{~mol} / \mathrm{L} ; 3.1 \times 10^{-3} \mathrm{~mol} / \mathrm{L}\right.$; $2.6 \times 10^{-3} \mathrm{~mol} / \mathrm{L} ; 2.2 \times 10^{-3} \mathrm{~mol} / \mathrm{L} ; 2.0 \times 10^{-3} \mathrm{~mol} / \mathrm{L}$ ) were added dropwise. The coordination reactions between PSCBS and $\mathrm{Eu}^{3+} / \mathrm{Yb}^{3+}$ were placed for $48 \mathrm{~h}$ at room temperature and with stirring (the molar ratio of ligand salicylaldehyde hydrazone to $\mathrm{Eu}^{3+} / \mathrm{Yb}^{3+}$ was 3:1). The solution was filtered, and $200 \mathrm{~mL}$ distilled water and $1.0 \mathrm{~g}$ sodium chloride were added to the filtered with constant stirring. Then, the precipitate was collected by filtration, washed with distilled water and dried under vacuum. These products were transferred into several volumetric flasks $(200 \mathrm{~mL})$, and their volume was made constant with DMF by forming six solutions of complex PSCBS-Eu(III)/Yb(III).

Those complexes were abbreviated as C1-0.5 (butyl acrylate and styrene molar ratio as 1:0.5), C1-1 (molar ratio as 1:1), C1-1.5 (molar ratio as 1:1.5), C1-2 (molar ratio as 1:2), C1-2.5 (molar ratio as 1:2.5).

\subsection{Physical characterization}

Elemental analyses (C, N, and $\mathrm{H}$ ) were determined with an Elementar Cario EL elemental analyzer. Fourier transform infrared spectra were recorded on $\mathrm{KBr}$ disk using Nexus 670 FT-IR spectrometer in $4000 \sim 500 \mathrm{~cm}^{-1}$ region. UV spectra were determined with a UV-2550 Ultraviolet Visible Spectrophotometer. Fluorescence excitation spectra of PSCBS-Eu(III)/Yb(III) were determined using a RF-5301 fluorescence spectrophotometer in the range of 200 900 nm. Differential scanning calorimetry (DSC) and thermo gravimetric analysis (TGA) were performed on a STA 449 C TG-DSC simultaneous thermal analyzer with a heating rate of $10 \mathrm{~K} / \mathrm{min}$ under a nitrogen atmosphere (flow rate: $40 \mathrm{~mL} / \mathrm{min}$ ).

\subsection{Determination of spectral performance of complexes}

\subsubsection{Determination of molecular weights and molecular weight distributions}

The molecular weights and molecular weight distributions of poly (styrene-co-butyl acrylate) were determined with a GPC1515 Gel permeation chromatograph. The mobile phase is DMF, flow velocity is $1 \mathrm{~mL} / \mathrm{min}$ and the concentration of solution is $1 \mathrm{mg} / \mathrm{mL}$.

\subsubsection{Determination of UV absorption spectrum}

UV spectra were determined with a UV-2550 Ultraviolet Visible Spectrophotometer. The solutions of PSCBS and PSCBS-Eu(III)/Yb(III) were prepared in DMF. The PSCBS concentrations in the two solutions were $1 \times 10^{-4} \mathrm{M}$.

\subsubsection{Determination of fluorescence emission spectrum}

Fluorescence excitation spectra of PSCBS-Eu(III)/Yb(III) were determined using a RF-5301 fluorescence spectrophotometer in the range of $200 \sim 900 \mathrm{~nm}$. The solutions of PSCBS-Eu(III)/Yb(III) complexes were placed into six conical flasks of $50 \mathrm{~mL}$ followed by adding of $40 \mathrm{~mL}$ DMF. Their concentrations were $1 \times 10^{-4} \mathrm{M}$. The excitation peak in the fluorescence emission spectra of these complexes was taken at $433 \mathrm{~nm}$.

\section{Results and discussion}

\subsection{Synthesis to prepare complexes PSCBS-Eu(III)/Yb(III)}

The aromatic acyl hydrazone ligands were bonded onto the side chains of poly (styrene-co-butyl acrylate), and the functional polymer PSCBS was obtained. The molecular weights and molecular weight distributions as well as the glass transition temperatures of the poly (styreneco-butyl acrylate) were given in Table 1. Finally, the coordination reaction between the macromolecular ligand PSCBS and $\mathrm{Eu}^{3+} / \mathrm{Yb}^{3+}$ ion was carried out in DMF, and the 
polymer-rare earth complex PSCBS-Eu(III)/Yb(III) was prepared. The preparation procedures and structural characterization methods had been described detailed previously. The Synthesis for preparing the functional polymer PSCBS and the complexes PSCBS-Eu(III)/Yb(III) were illustrated in Scheme 1 (1).

Table 1: GPC data of poly (styrene-co-butyl acrylate).

\begin{tabular}{|c|c|c|c|}
\hline Copolymer & $\mathrm{Mn}(\mathrm{Kg} / \mathrm{mol})$ & $\mathrm{Mw}(\mathrm{Kg} / \mathrm{mol})$ & PDI \\
\hline $\begin{array}{l}\text { poly(styrene-co-butyl } \\
\text { acrylate) } 1: 0.5\end{array}$ & 66749 & 215073 & 3.22 \\
\hline $\begin{array}{l}\text { poly(styrene-co-butyl } \\
\text { acrylate) } 1: 1\end{array}$ & 58921 & 150480 & 2.55 \\
\hline $\begin{array}{l}\text { poly(styrene-co-butyl } \\
\text { acrylate) } 1: 1.5\end{array}$ & 51402 & 121402 & 2.36 \\
\hline $\begin{array}{l}\text { poly(styrene-co-butyl } \\
\text { acrylate) } 1: 2\end{array}$ & 50047 & 108747 & 2.17 \\
\hline $\begin{array}{l}\text { poly(styrene-co-butyl } \\
\text { acrylate) } 1: 2.5\end{array}$ & 49721 & 104329 & 2.10 \\
\hline
\end{tabular}

Noteworthy, the PSCBS solution is a diluted solution. The coordination reaction among PSCBS and the $\mathrm{Eu}^{3+} / \mathrm{Yb}^{3+}$ ion occurs in an intramolecular action. It is suggested that the salicylaldehyde ligands hanging from the same macromolecule chain would coordinate to the $\mathrm{Eu}^{3+} / \mathrm{Yb}^{3+}$, and an intrachain complex would formed, as shown in Scheme 1 (2).

\subsection{Analytical and physical data of the Schiff base polymer PSCBS}

The contents of $\mathrm{C}, \mathrm{H}$, and $\mathrm{N}$ in the sample were determined by elemental analyses. The results were listed in Table 2. The results shows the content of $\mathrm{C}$, $\mathrm{H}$, and $\mathrm{N}$ measured in the compound not very different from the theoretical value. So the experimental values of the element analysis suggested that Schiff base polymer PSCBS have been synthetized.

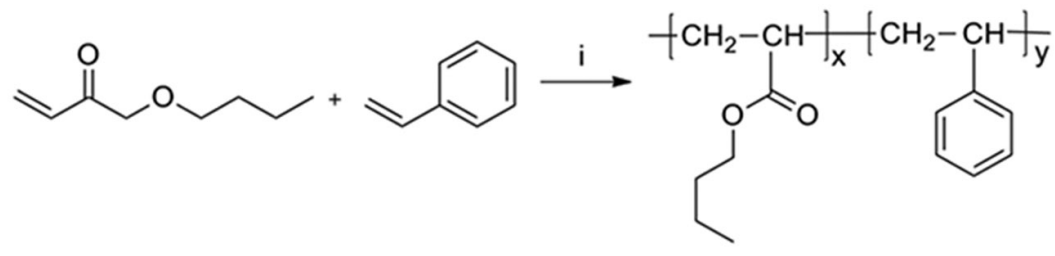

i $\mathrm{BDO}, 80^{\circ} \mathrm{C}$

II $\mathrm{NH}_{2} \mathrm{NH}_{2} \cdot \mathrm{H}_{2} \mathrm{O}, 30^{\circ} \mathrm{C}$

III THF, $70^{\circ} \mathrm{C}$, reflux<smiles>CC#CC=Cc1ccccc1O</smiles>

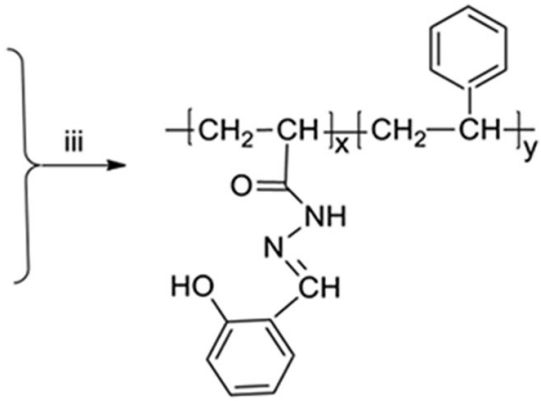

(1) Schiff base reaction between the ester group of poly (styrene-co-butyl acrylate) and amino group of salicylaldehyde hydrazine

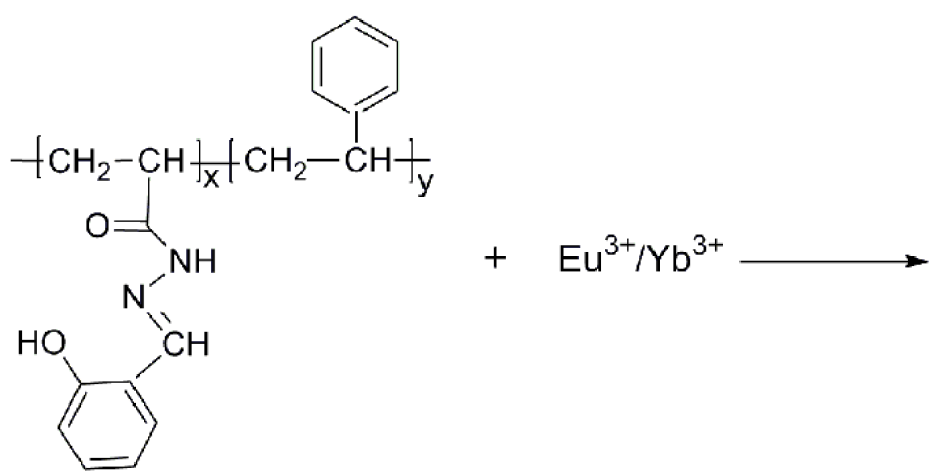

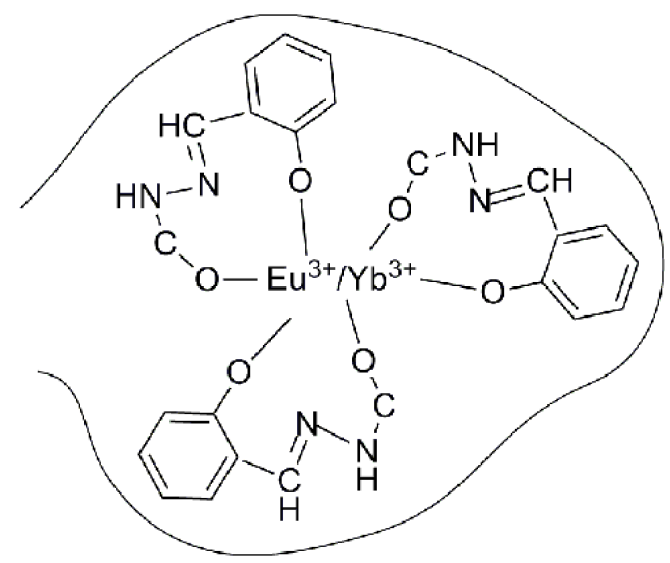

(2) Coordiation reaction between macromolecule PSCBS and $\mathrm{Eu}^{3+} / \mathrm{Yb}^{3+}$

Scheme 1: Reaction pathways Schematic expression of synthesis of preparation of complex PSCBS-Eu(III)/Yb(III). 
Table 2: Analytical data of PSCBS.

\begin{tabular}{lrrr}
\hline compounds & $\mathbf{C} / \%$ & $\mathbf{H} / \%$ & $\mathbf{N} / \%$ \\
\hline PSCBS 1-0.5 & 72.92 & 7.75 & 2.90 \\
PSCBS 1-1 & 74.73 & 8.11 & 1.89 \\
PSCBS 1-1.5 & 79.71 & 8.08 & 1.85 \\
PSCBS 1-2 & 80.81 & 7.91 & 1.85 \\
PSCBS 1-2.5 & 78.67 & 8.37 & 1.54 \\
\hline
\end{tabular}

\subsection{Infrared spectrum of PSCBS and their complexes}

In the IR spectrum of PSCBS (Figure 1), except for the characteristic bands of poly (styrene-co-butyl acrylate), there are some bands due to salicylaldehyde hydrazone moiety. The band at $1,619 \mathrm{~cm}^{-1}$ is attributed to the stretching vibration absorption of $-\mathrm{C}=\mathrm{N}-$ bond of the Schiff base, showing that the Schiff base reaction between poly(styrene-co-butyl acrylate) and salicylaldehyde hydrazone has occurred, indicating that salicylaldehyde hydrazone ligands have been bonded onto the side chains of poly(styrene-co-butyl acrylate). The stretching vibration absorption peak of the carbonyl group and the bending vibration absorption peak of phenolic hydroxyl group of the polymer functionalized with the Schiff base have appeared at $1,726 \mathrm{~cm}^{-1}$ and $1,248 \mathrm{~cm}^{-1}$, respectively.

In the spectrum of PSCBS-Eu(III)/Yb(III) (Figure 2), compared to the infrared spectrum of PSCBS, the peak corresponding to the carbonyl group was transferred from $1,726 \mathrm{~cm}^{-1}$ to $1,733 \mathrm{~cm}^{-1}$, showing that the carboxyl group of BA has participated in the coordination to $\mathrm{Eu}^{3+} / \mathrm{Yb}^{3+}$ ion. The stretching vibration absorption of $-\mathrm{C}=\mathrm{N}-$ bond of Schiff base has weakened greatly, indicating that the $-\mathrm{C}=\mathrm{N}-$ bond of the Schiff base has participated in the coordination to $\mathrm{Eu}^{3+} / \mathrm{Yb}^{3+}$ ion. The bending vibration absorption of phenolic hydroxyl group at $1,248 \mathrm{~cm}^{-1}$ has shifted to $1,270 \mathrm{~cm}^{-1}$, whereas the absorption of phenolic hydroxyl group has weakened greatly, showing that the phenolic hydroxyl group of salicylaldehyde hydrazone has participated in the coordination to $\mathrm{Eu}^{3+} / \mathrm{Yb}^{3+}$ ion. So based on the facts that the ligand salicylaldehyde hydrazone on the side chains of PSCBS has coordinated to $\mathrm{Eu}^{3+} / \mathrm{Yb}^{3+}$ ion in a bidentate coordination form, and forming the polymer rare earth complex PSCBS-Eu(III)/Yb(III).

\subsection{UV absorption spectrum of PSCBS and their $\mathrm{Eu}(\mathrm{III}) / \mathrm{Yb}$ (III) complexes}

Figure 3 shows the UV absorption spectra of the PSCBS. In the Figure 3, There are two absorption peaks at about

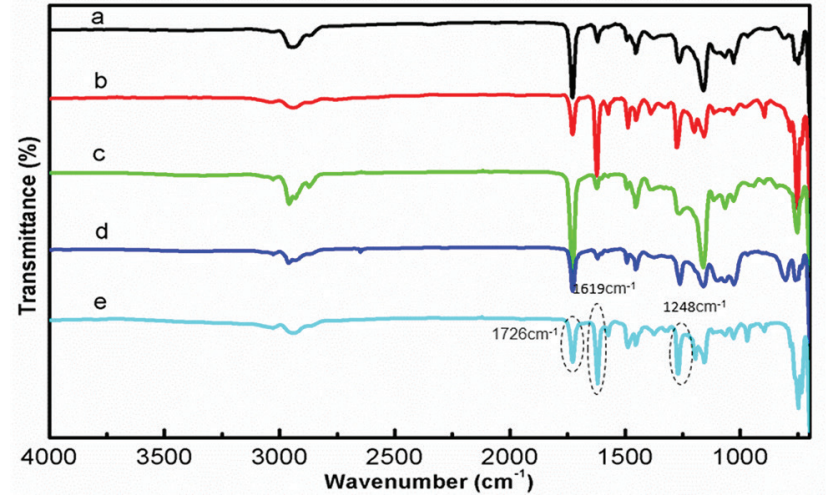

Figure 1: Infrared spectra of PSCBS (a: P 1-0.5 b: P 1-1 c: P 1-1.5 d: P 1-2 e: P 1-2.5).

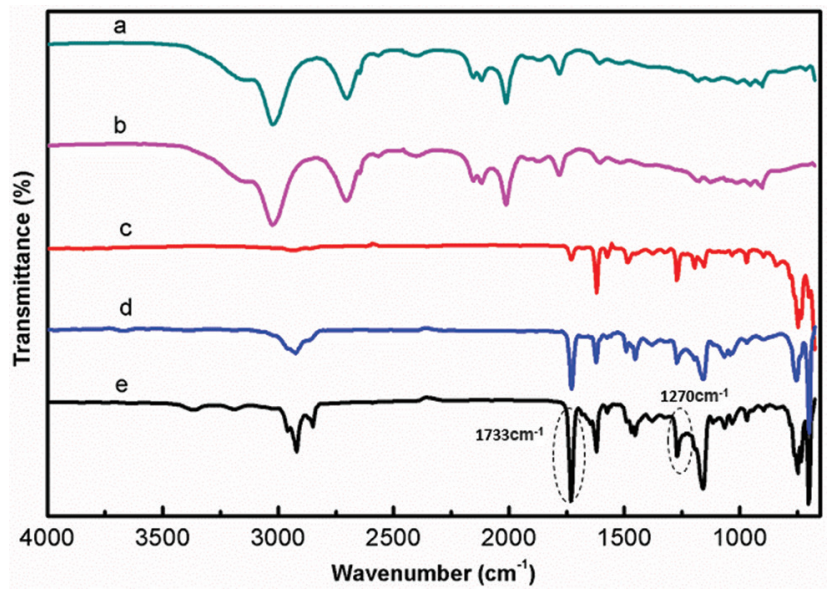

Figure 2: Infrared spectra of PSCBS-Eu(III)/Yb(III) (a: C 1-0.5 b: C 1-1 c: C 1-1.5 d: C 1-2 e: ( 1-2.5).

$294 \mathrm{~nm}$ and $354 \mathrm{~nm}$. The former peak is primarily owed to the $\pi^{\star}-\pi^{\star}$ electron transition of the benzene ring of polystyrene backbone. The latter peak is assigned to the $n-\pi^{\star}$ electron transition of the keto and enol tautomerism of Schiff base ligands. The UV spectra of the polymer rare earth complexes (Figure 4) are similar to that of PSCBS in spectrum shape and the peak positions, and only the characteristic absorption intensities were reduced. The reduced absorption peak of the complexes imply that the Schiff base ligand of the polymer PSCBS has coordinated to $\mathrm{Eu}^{3+} / \mathrm{Yb}^{3+}$ and the polymer rare earth complex PSCBS$\mathrm{Eu}(\mathrm{III}) / \mathrm{Yb}(\mathrm{III})$ has been formed.

\subsection{Thermal analysis of PSCBS and their $\mathrm{Eu}(\mathrm{III}) / \mathrm{Yb}$ (III) complexes}

The thermal analysis curves of the PSCBS was depicted in Figure 5. In the present study, the weight loss was 


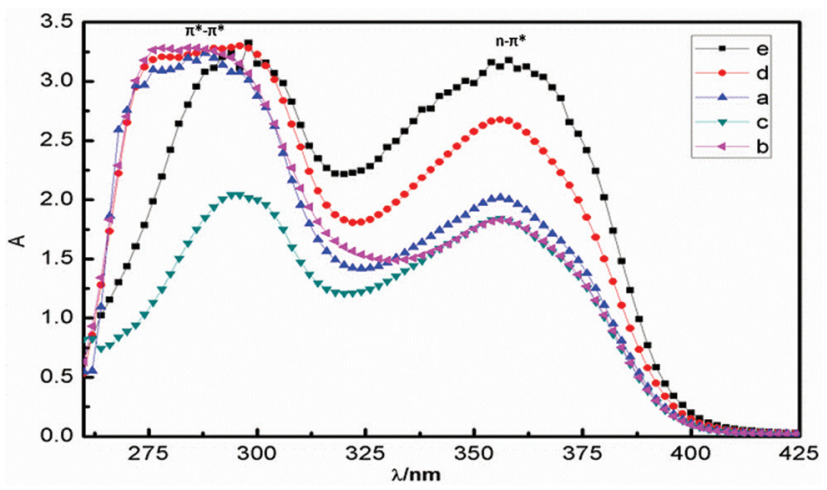

Figure 3: UV absorption spectrum of PSCBS (a: P 1-0.5 b: P 1-1 c: P 1-1.5 d: P 1-2 e: P 1-2.5).

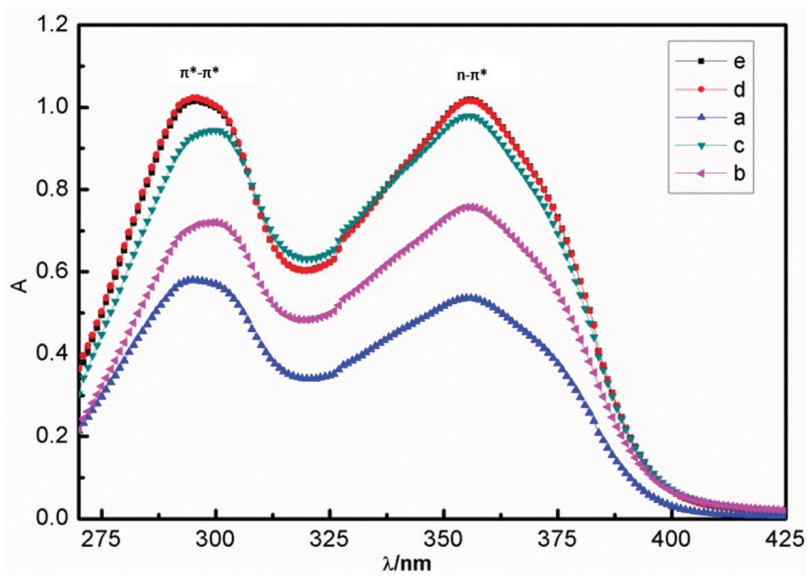

Figure 4: UV absorption spectrum of PSCBS-Eu(III)/ $\mathrm{Yb}$ (III) (a: C 1-0.5 b: C 1-1 c: C 1-1.5 d: C 1-2 e: C 1-2.5).

measured from the ambient temperature up to $800^{\circ} \mathrm{C}$. From TGA curves we can see that, all samples showing good thermal stability and show two main degradation steps. A slight weight loss of five samples happened at the temperatures over $160^{\circ} \mathrm{C}$ because of desorption of physically adsorbed water and residual solvent THF. The $20 \%$ weight loss took place in the temperature range of $180^{\circ} \mathrm{C} \sim 350^{\circ} \mathrm{C}$ may be attributed to the loss of some aromatic fragments, without any decomposition of the chemical bond. With the increase of styrene molar ratio, the amount of weight loss increased gradually. On further heating, the TGA curve exhibited decomposition of the organic molecular chains of PSCBS till a complete weight loss, which is accompanied by an endothermic process in the DSC curves (not given).

Differential scanning calorimetry (DSC) and thermo gravimetric analysis (TGA) are performed on all the complexes. Figure 6 shows the TGA traces of complex C1-0.5, C1-1, C1-1.5, C1-2 and C1-2.5. From the TGA curves we can see that all samples show similar weight loss trend

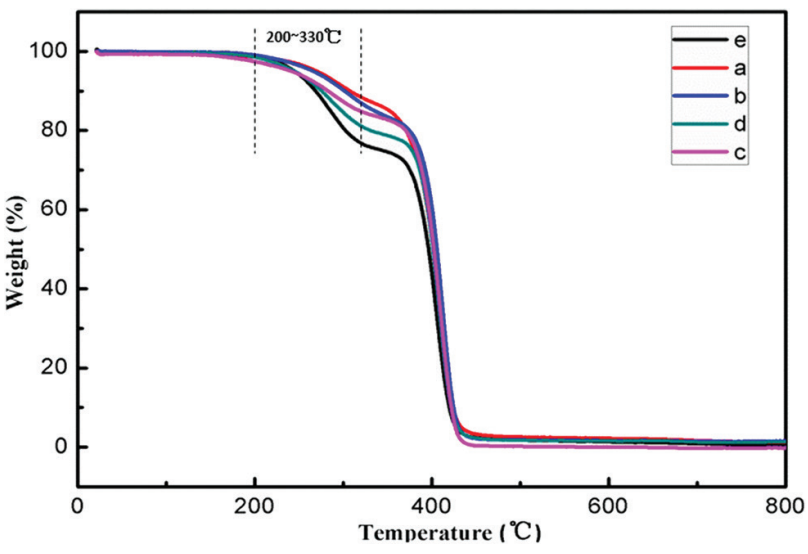

Figure 5: Thermal spectra of PSCBS (a: P 1-0.5 b: P 1-1 c: P 1-1.5 d: P 1-2 e: P 1-2.5).

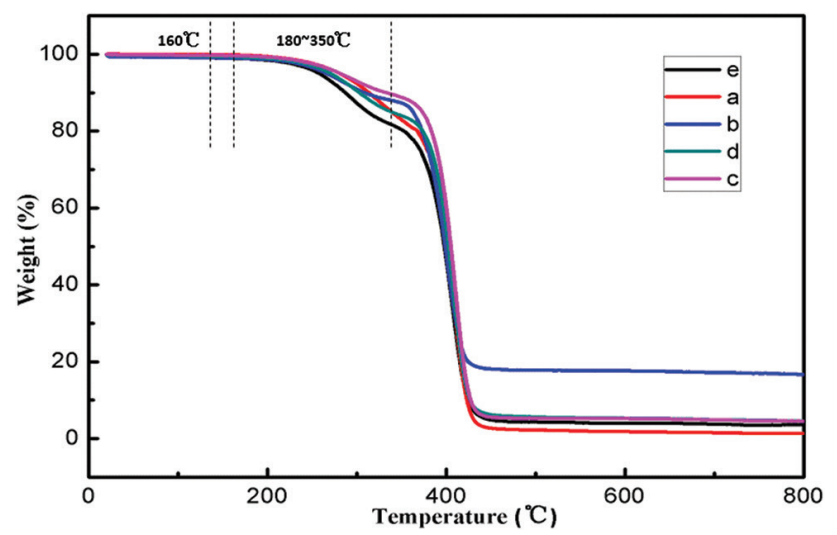

Figure 6: Thermal spectra of PSCBS-Eu(III)/Yb(III) (a: C 1-0.5 b: C 1-1 c: C 1-1.5 d: C 1-2 e: ( 1-2.5).

in, and two main degradation steps can be obviously observed. The initial weight loss occurring in the temperature range $200 \sim 330^{\circ} \mathrm{C}$ is interpreted as loss of crystal water molecules and coordinated water molecules for PSCBS-Eu(III)/Yb(III) complexes. Degradation of the ligand was observed in the range of $330 \sim 430^{\circ} \mathrm{C}$. At 430 , the complex completely converts into $\mathrm{Eu}_{2} \mathrm{O}_{3} / \mathrm{Yb}_{2} \mathrm{O}_{3}$, and the weight becomes stable. Compared with the organic compound PSCBS, whose melting point is only $80 \sim 110^{\circ} \mathrm{C}$, thermal stabilities of this kind of complexes are largely improved. This improvement of thermal stability is interpreted by the formation of the $\mathrm{M}-\mathrm{O}$ bond.

\subsection{Fluorescence emission intensity dependence on salicylaldehyde hydrazine ligand amount for the complex PSCBS-Eu(III)/Yb(III)}

The fluorescence excitation spectrum of PSCBS$\mathrm{Eu}(\mathrm{III}) / \mathrm{Yb}(\mathrm{III})$ was obtained by monitoring the emission 


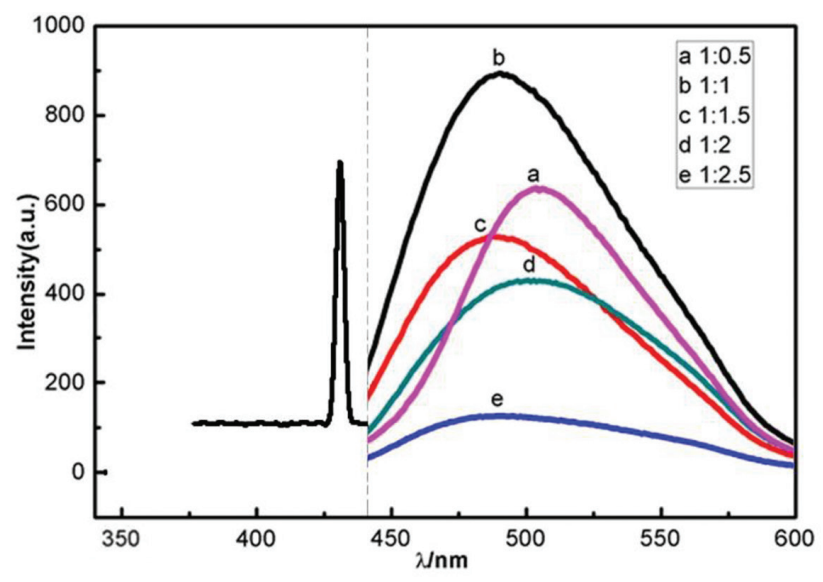

Figure 7: Fluorescence emission spectrum of PSCBS-Eu(III)/Yb(III) (a: C1-0.5 b: C1-1 c: C1-1.5 d: C1-2 e: C1-2.5).

of $\mathrm{Eu}^{3+} / \mathrm{Yb}^{3+}$ at $497 \mathrm{~nm}$, and the peak at $433 \mathrm{~nm}$ was found to be the optimal excitation peak. By exciting at $433 \mathrm{~nm}$, the fluorescence emission spectrum of PSCBS-Eu(III)/Yb(III) in DMF solution was decided. By fixing the concentration of $\mathrm{Eu}^{3+} / \mathrm{Yb}^{3+}$ in the solution, the concentration of salicylaldehyde hydrazone ligand was changed gradually and the molar ratio of the butyl acrylate to styrene changed to $(1: 0.5 ; 1: 1 ; 1: 1.5 ; 1: 2 ; 1: 2.5)$, and the fluorescence emissions of the complex PSCBS-Eu(III)/Yb(III) in these solutions were decided. The results are displayed in Figure 7.

In Figure 7, the following results are showed: (1) the fluorescence emission of the complex PSCBS$\mathrm{Eu}(\mathrm{III}) / \mathrm{Yb}$ (III) (e) is very weak and the concentration of salicylaldehyde hydrazone in the solution is small as seen in the analytical and physical data of the Schiff base polymer PSCBS (Table 1). (2) the fluorescence emission of the complex PSCBS-Eu(III)/Yb(III) increased the molar ratio of butyl acrylate to styrene, and reached a maximum value in the molar ratio of 1:1. The maximum luminescent intensity was observed at $489 \mathrm{~nm}$, and the half width maximum was about $100 \mathrm{~nm}$. Therefore, the fluorescence emission of the PSCBS-Eu(III)/Yb(III) was mainly sensitized by the absorption of the salicylaldehyde hydrazone group on the side chains of macromolecule ligand PSCBS.

\section{Conclusions}

In conclusion, with the poly (styrene-co-butyl acrylate) and salicylaldehyde hydrazone as starting materials, a serial of novel Schiff-base polymer were obtained. On the basis of the functionalized PSCBS ligand, the polymer rare earth complex of PSCBS-Eu(III)/Yb(III) was prepared, and its fluorescence emission property was researched amply. The bonded salicylaldehyde hydrazone as a bidentate ligand can link to $\mathrm{Eu}^{3+} / \mathrm{Yb}^{3+}$ and take shape firmer polymer-rare earth complex PSCBS-Eu(III)/Yb(III). The macromolecular ligand PSCBS can strongly activate the fluorescence emission of the center ion due to the effective intramolecular energy transfer. More significantly, all the $\mathrm{Eu}(\mathrm{III}) / \mathrm{Yb}(\mathrm{III})$ complexes exhibit characteristic photoluminescence in the visible region, indicating that these complexes may be interesting materials for application in the field of light-emitting field.

Acknowledgments: The authors are grateful to the National Natural Science Foundation of China (Grant No. 51663013) and the Science foundation of State Key Laboratory of Advanced Processing and Recycling of Non-ferrous Metals.

\section{References}

1. Xu H., Zhu R., Zhao P., Huang W., Monochromic Red-Emitting Nonconjugated Copolymers Containing Double-Carrier-Trapping Phosphine Oxide Eu ${ }^{3+}$ Segments: Toward Bright and Efficient Electroluminescence. J Phys Chem C, 2011, 115(31), 15627-15638.

2. Gao B., Fang L., Zhang R., Men J., Preparation of aromatic carboxylic acid-functionalized polysulfone and preliminary exploration of florescence emission character of formed polymer-rare earth complexes. Synthet Metals, 2012, 162(5), 503-510.

3. Gao B., Fang L., Men J., Studies on preparation, structure and fluorescence emission of polymer-rare earth complexes composed of aryl carboxylic acid-functionalized polystyrene and Tb(III) ion. Polymer, 2012, 53(21), 4709-4717.

4. Liu D., Wang Z., Yu H., You J., Fluorescence properties of novel rare earth complexes using carboxyl-containing polyaryletherketones as macromolecular ligands. Eur Polym J, 2009, 45(8), 2260-2268.

5. Ma P.C., Siddiqui N.A., Marom G., Kim J.-K., Dispersion and functionalization of carbon nanotubes for polymer-based nanocomposites: a review. Composites A: Appl Sci Manufact, 2010, 41(10), 1345-1367.

6. Bünzli J.C.G., Eliseeva S.V., Lanthanide NIR luminescence for telecommunications, bioanalyses and solar energy conversion. J Rare Earths, 2010, 28(6), 824-842.

7. Rocha J., Carlos L.D., Paz F.A.A., Ananias D., Luminescent multifunctional lanthanides-based metal-organic frameworks. Chem Soci Rev, 2011, 40(2), 926-940.

8. Jiang J., Zhang C., Lin W., Liu Y., Liu S., Xu Y., et al., Long-Lived Phosphorescent Iridium(III) Complexes Conjugated with Cationic Polyfluorenes for Heparin Sensing and Cellular Imaging. Macromol Rapid Commun, 2015, 36(7), 640-646.

9. Sun Y., Yang B., Guo G., Liu Y., Zhao G., Controlled Formation of Sm(III) Doping Polymer Thin Films Based on a New Macroligand with $\beta$-Diketonate. J Inorg Organomet Polym Mater, 2011, 21(3), 395-399. 
10. Yu Y., Wang J., Zhu Y., Ge M., Researches on preparation and properties of polypropylene nonwovens containing rare earth luminous materials. J Rare Earths, 2014, 32(12), 1196-1200.

11. Zhang Y., Zhang J., Cui Z., Chen Q., Zhang H., Jiang Z., Fabrication of fluorescent holographic micropatterns based on the rare earth complexes using azobenzene-containing poly(aryl ether)s as macromolecular ligands. J Polymer Sci A: Polymer Chem, 2015, 53(7), 936-943.

12. Gao B., Zhang W., Zhang Z., Lei Q., Preparation of polymer-rare earth complex using salicylic acid-containing polystyrene and its fluorescence emission property. J Luminescence, 2012, 132(8), 2005-2011.

13. Guo X., Zhu G., Fang Q., Xue M., Tian G., Sun J., et al., Synthesis, structure and luminescent properties of rare earth coordination polymers constructed from paddle-wheel building blocks. Inorg Chem, 2005, 44(11), 3850-3855.

14. Gao B., Qiao Z., Chen T., Structure and photoluminescence property of complexes of aromatic carboxylic acid-functionalized polysulfone with $\mathrm{Eu}(\mathrm{III})$ and $\mathrm{Tb}(\mathrm{III})$. Mater Chem Phys, 2014, 143(3), 1119-1130.

15. Tian G., Zhang Z., Martin L.R., Rao L.,, Complexation of Curium (III) with DTPA at $10-70^{\circ} \mathrm{C}$ : Comparison with Eu (III)-DTPA in Thermodynamics, Luminescence, and Coordination Modes. Inorg Chem, 2015, 54(4), 1232-1239.

16. Gao B., Fang L., Men J., Studies on preparation, structure and fluorescence emission of polymer-rare earth complexes composed of aryl carboxylic acid-functionalized polystyrene and $\mathrm{Tb}$ (III) ion. Polymer, 2012, 53(21), 4709-4717.

17. Wang M., Gao B., Du J., Preparation of Naphthoic Acid-functionalized Polysulfone and Preliminary Exploration of Fluorescence Emission of Formed Polymer-Rare Earth Eu(III) Complexes. Chin J Appl Chem, 2013, 3, 006.

18. Li Q.P., Yan B., Novel luminescent hybrids by incorporating rare earth $\beta$-diketonates into polymers through ion pairing with an imidazolium counter ion. Photochem Phoobiol Sci, 2013, 12(9), 1628-1635.

19. Decadt R., Van Hecke K., Depla D., Leus K., Weinberger D., Van Driessche I., et al., Synthesis, crystal structures, and luminescence properties of carboxylate based rare-earth coordination polymers. Inorg Chem, 2012, 51(21), 11623-11634.

20. Zeng Z., Zhou J., Zhang Y., Qiao R., Xia S., Chen J., et al., Photodynamic properties of hypocrellin $A$, complexes with rare earth trivalent ions: role of the excited state energies of the metal ions. J Phys Chem B, 2007, 111(10), 2688-2696.

21. Mathew N., Studies on metal complexes of some tridentate acylhydrazones. Cochin University of Science and Technology, 2011, 21.

22. Kumar D., Chadda S., Sharma J., Surain P., Syntheses, Spectral Characterization, and Antimicrobial Studies on the Coordination Compounds of Metal Ions with Schiff Base Containing Both Aliphatic and Aromatic Hydrazide Moieties. Bioinorg Chem Application, 2013, 2013(4), 981764.

23. Shen L., Shi M., Li F., Zhang D., Li X., Shi E., et al., Polyaryl ether dendrimer with a 4-phenylacetyl-5-pyrazolone-based terbium(III) complex as core: synthesis and photopysical properties. Inorg Chem, 2006, 45(16), 6188-6197.

24. Sankar R., Studies on poly (Acrylate)s containing hydrazone ligand derived from 2,4-Dihydroxy carbonyl compounds and their divalent metal complexes. 2012, 84(9), 1059-1065

25. Cheng X., Tang R., Jia H., Feng J., Qin J., Li Z., New fluorescent and colorimetric probe for cyanide: direct reactivity, high selectivity, and bioimagingapplication. ACS Appl Mater Interfaces, 2012, 4(8), 4387-4392.

26. Popov L.D., Morozov A.N., Shcherbakov I.N., Tupolova Y.P., Lukov V.V., Kogan V.A., Metal complexes with polyfunctional ligands based of bis(hydrazones) of dicarbonylcompounds. Russ Chem Rev, 2009, 78(7), 643-658.

27. Fukuzumi S., Yasui K., Suenobu T., Ohkubo K., Fujitsuka M., Ito O., Efficient catalysis of rare-earth metal ions in photoinduced electron-transfer oxidation of benzyl alcohols by a flavin analogue. J Phys Chem A, 2001, 105(46), 10501-10510.

28. Ling Q.D., Cai Q.J., Kang E.T., Neoh K.G., Zhu F.R., Huang W., Monochromatic light-emitting copolymers of $\mathrm{N}$-vinylcarbazole and Eu-complexed 4-vinylbenzoate and their single layer high luminance PLEDs. J Mater Chem, 2004, 14(18), 2741-2748. 